\title{
Catalytic Applications of Zeolites in Chemical Industry
}

\author{
Bilge Yilmaz • Ulrich Müller
}

Published online: 14 April 2009

(c) The Author(s) 2009. This article is published with open access at Springerlink.com

\begin{abstract}
New materials are prerequisite for major breakthrough applications influencing our daily life, and therefore are pivotal for the chemical industry. Nanoporous materials constitute an important class of heterogeneous catalysts as they not only offer higher surface areas and enhanced activity, but also provide shape/size selectivity. As a well-established family of nanoporous materials, zeolites are of paramount importance for the chemical industry as heterogeneous catalysts with shape/size-selective character in various reactions. Zeolites can also play an active role in the quest for raw material change as catalysts providing the required selectivity towards base chemicals. In this contribution, an overview of the current and potential applications of zeolites as catalysts in chemical industry is presented.
\end{abstract}

Keywords Heterogeneous catalysis - Zeolites · Industrial chemistry $\cdot$ Nanotechnology .

Raw material change

\section{Introduction}

Due to its role in many crucial chemical processes, heterogeneous catalysis is one of the key elements of our industrialized society, and thus has direct impact on the global economy. It is reported that approximately nine-outof-ten chemical processes utilize heterogeneous catalysts

B. Yilmaz · U. Müller ( $₫)$

BASF SE, Chemicals Research and Engineering, GCC/PZ,

Ludwigshafen 67056, Germany

e-mail: ulrich.mueller@basf.com
[1]. Global catalyst market is estimated to be between 15 and 20 billion USD annually. Approximately half of this market is geared directly towards the chemical industry and the rest is divided between environmental and refinery applications. The annual combined worth of the products obtained from industrial catalytic processes (including refinery operations) is estimated to be at a multi-trillion USD level. Therefore, it can be stated that the value created by utilizing catalysts is approximately three orders of magnitude higher than the amount invested in them.

Shape and size selectivity is a vital consideration for many industrial catalytic processes, and it is typically attained by utilizing catalysts of nanoporous nature. Selectivity can be based on the shape/size of the reactant, product or intermediate. In order to provide such shape/size selective behavior, the catalyst must have uniform pores with molecular dimensions. Uniform porosity is the outcome of a highly ordered structure, such as in zeolitic frameworks, where pores/channels are part of the building blocks (i.e., repetitive units). Zeolites are made of threedimensional crystalline networks that preferentially adsorb molecules and exclude larger ones. Each nanoporous material has the potential to offer unique structural and chemical features that can be beneficial for an industrial application. For zeolites, the ability to exchange cations is another essential feature for applications in catalysis. As a result of their high surface areas, nanoporous catalysts contain a higher density of active sites that are directly involved in the reaction at a molecular level. This characteristic results in enhanced activity, and thus a more effective catalytic system. Owing to the Angstrom-scaled features they possess, zeolites and other nanoporous materials also present significant potential for future utilization in numerous advanced applications in the fields of nanotechnology [2,3] and biotechnology [4]. 


\section{Industrial Interest in Zeolites}

Systematic research efforts on synthesis and adsorption properties of zeolites were initiated by Richard M. Barrer in the late 1930's. Following his pioneering work, researchers at Union Carbide developed procedures for preparation of the first synthetic zeolites (e.g., zeolites A, $\mathrm{X}$, and $\mathrm{Y}$ ) that would find industrial applications (in oil refining). The commercial impact of the introduction of zeolites into refinery operations has been immense, as it resulted in $\sim 30 \%$ increase in gasoline yield, thus more efficient utilization of the petroleum feedstocks.

Based on this successful entry into the industrial scene, zeolites quickly found many applications in petroleum processing in subsequent years. Since then about 20 different zeolitic framework structures have been commercialized for utilization in industrial processes. Worldwide consumption of synthetic zeolites is estimated at about 1.7-2 million metric tons per year [5-7]. For natural zeolites the annual consumption is approximately 2.5 million metric tons [5]. Traditionally the major applications for synthetic zeolites are in detergents, adsorbents/desiccants and catalysis. The current global market for synthetic zeolites is estimated to be around 2 billion USD annually.

\subsection{Zeolites as Catalysts in Industrial Processes}

It has been four decades since the introduction of the shape-selective character of zeolites into industrial applications. In these four decades utilization of zeolites in catalysis has increased dramatically. Consumption of zeolites as catalysts accounts for an estimated $27 \%$ of the world zeolite market on a value basis [5]. Four major companies control more than three quarters of the global zeolite catalyst market. Fluid catalytic cracking (FCC) catalysts (primarily USY zeolite) constitute more than $95 \%$ of zeolite catalyst consumption [5]. The largest volume of zeolite catalyst consumption is in North America with 83 thousand metric tons (anhydrous) per year [5]. Approximately 35 thousand metric tons of zeolite is consumed in Europe, and 11 thousand metric tons of zeolites are used in Japan every year [5]. Overall, the worldwide zeolite catalyst consumption sums up to approximately 241 thousand metric tons (anhydrous) per year [5]. Comparison of the annual zeolite catalyst consumption by regions is presented in Fig. 1.

As a result of the rapid development of the Chinese chemical and petrochemical industries in the last two to three decades, and with increasing presence of international chemical companies, the demand for zeolite catalysts in China has increased significantly. In order to keep up with this demand there are currently close to 20 different producers of zeolite catalysts operating in various locations in

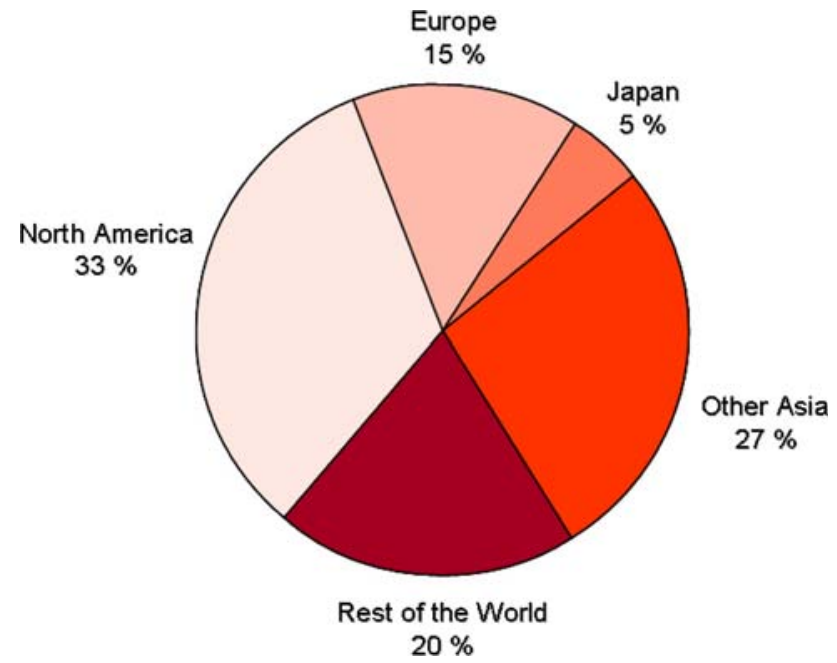

Fig. 1 Annual zeolite catalyst consumption by region

China. The total production capacity is estimated to be above 12 thousand metric tons per year. Most of this capacity ( $\sim 98 \%)$ is used for ZSM-5 production.

In chemical industry some examples of zeolite-catalyzed processes that are currently in operation include hydroxylation (e.g., phenol), alkylation (e.g., ethylbenzene, cumene), oximation (e.g., cyclohexanone oxime) and epoxidation (e.g., propylene oxide). Many of these zeolite-catalyzed chemical processes have been developed in Japan. In Table 1, some examples of chemical products obtained by zeolite-catalyzed processes developed in Japan and the zeolite structures used as catalysts in these processes are presented. The catalysts for industrial processes are selected based on the distinct structural, morphological and compositional characteristics of the zeolite and the needs/ limitations of the reaction. Compatibility of the zeolite catalyst with the reaction can be considered as the key for the economic success of the process. In order to achieve this compatibility, for some processes the zeolite catalyst needs to go through various post-synthesis modifications. Such modifications can have substantial impact on the financial outcome. For example, in large scale zeolite-catalyzed chemical processes such as ethyl benzene manufacturing or propylene oxide production (HPPO process by BASFDow joint venture) with output of several hundred thousand tons per year, even an increase of $1 \%$ in catalyst selectivity contributes to some additional thousand tons of product. The simplified flowsheet describing the HPPO process is presented in Fig. 2.

\subsection{Zeolites as Catalysts in Environmental Applications}

Over the course of years the field of zeolites has greatly benefited from the increasing environmental consciousness of the society. As detergent builders, zeolites replaced 
Table 1 Examples of zeolite-catalyzed chemical processes developed in Japan

\begin{tabular}{|c|c|c|c|}
\hline Product & Zeolite structure & Technology owner & Ref. \\
\hline & MFI & Asahi Chemical Ind. Co. Ltd. & {$[8]$} \\
\hline & MFI & Sumitomo Chemical Co. Ltd. & [9] \\
\hline & MFI & Sumitomo Chemical Co. Ltd. & {$[10]$} \\
\hline & MOR & Nitto Chemical Ind. Co. Ltd. & [11] \\
\hline & MWW & Showa Denko K. K. & [12] \\
\hline & MFI & Tosoh Corp. & [13] \\
\hline & MFI & Nippon Shokubai Co. Ltd. & [14] \\
\hline
\end{tabular}

Fig. 2 Simplified flowsheet of the HPPO process

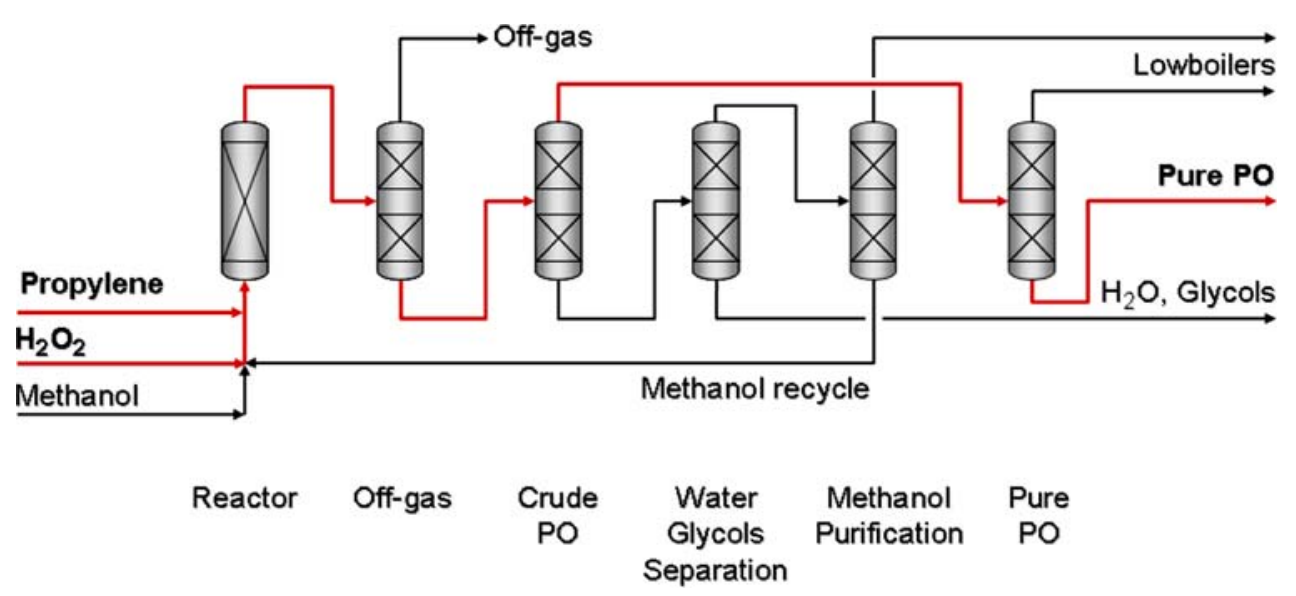


sodium phosphates, which were shown to distort the balance of the freshwater ecosystems. Being the environmentally friendly alternative, zeolites quickly increased their share in the laundry detergent market. Today, utilization as detergent builders makes up the largest use of synthetic zeolites in terms of volume [5]. In refineries consumption of zeolite catalysts has increased as a result of the environmentally driven policies to decrease sulfur emissions [5]. Also, in order to enhance the light olefin yields, the FCC catalyst compositions were modified by increasing the zeolite loadings and by introducing different types of zeolite structures [5]. Zeolites have also replaced (or have been proposed to replace) the conventional catalysts in many industrial processes as the environmentally benign alternatives.

With increasing environmental regulations to fight air pollution, (and thus global warming), new applications opened up for zeolite catalysts. In Europe, North America and Japan progressively more and stricter regulations are being implemented to reduce the $\mathrm{NO}_{x}$ emissions from stationary and mobile applications. Selective Catalytic Reduction (SCR) is currently the leading technology to revert the formed $\mathrm{NO}_{x}$ into harmless $\mathrm{N}_{2}$ and $\mathrm{H}_{2} \mathrm{O}$ by using a reducing agent such as urea (ammonia). For the stoichiometric $\mathrm{NH}_{3}$-SCR reaction, the chemical equations are:

$$
\begin{aligned}
& 4 \mathrm{NO}+4 \mathrm{NH}_{3}+\mathrm{O}_{2} \rightarrow 4 \mathrm{~N}_{2}+6 \mathrm{H}_{2} \mathrm{O} \\
& 6 \mathrm{NO}_{2}+8 \mathrm{NH}_{3} \rightarrow 7 \mathrm{~N}_{2}+12 \mathrm{H}_{2} \mathrm{O} \\
& 2 \mathrm{NO}_{2}+4 \mathrm{NH}_{3}+\mathrm{O}_{2} \rightarrow 3 \mathrm{~N}_{2}+6 \mathrm{H}_{2} \mathrm{O} \\
& \mathrm{NO}+\mathrm{NO}_{2}+2 \mathrm{NH}_{3} \rightarrow 2 \mathrm{~N}_{2}+3 \mathrm{H}_{2} \mathrm{O}
\end{aligned}
$$

Zeolites are the preferred catalysts for diesel SCR as they can withstand high operating temperatures, which is essential in automotive SCR applications. This is a highly effective catalytic system as the zeolite catalyst can convert most of the $\mathrm{NO}_{x}$ during steady-state operation. With upcoming regulations on automotive $\mathrm{NO}_{x}$ emissions, the new generation of both light-duty and heavy-duty diesel vehicles will utilize this technology. Therefore, a significant zeolite catalyst demand from the automotive industry can be forecasted.

\section{Role of Zeolites in Raw Material Change}

The recent increase in oil prices brought the barrel price of crude oil to record high levels. Since crude oil is a major raw material for the chemical industry, these developments also emphasize the importance of considering change and flexibility of raw materials. Various alternatives for raw material change in chemical industry [15] are demonstrated in Fig. 3. Many of the processes involved in changing the raw material basis (e.g., coal, natural gas, renewables, other

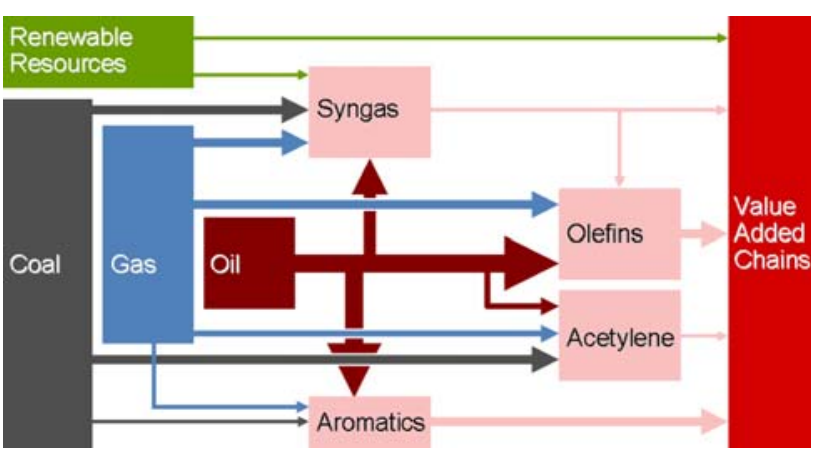

Fig. 3 Alternatives for raw material change in chemical industry

biomass) for chemical industry make use of zeolite catalysts. Therefore, the quest for implementing new raw materials in chemical industry involves zeolites.

If methanol is obtained from any of the raw materials, the process can be coupled with a Methanol-to-Olefins (MTO) unit to have the suitable input (e.g., ethylene, propylene) to enter the corresponding value added chain. Ethylene and propylene are crucial intermediates for chemical industry, and in terms of production volume they are among the largest. The global demand for ethylene and propylene has been increasing steadily; however, it should be noted that the propylene demand growth rate has been considerably higher than ethylene demand growth rate. Tightening of the worldwide propylene supply is expected, as conventional routes for propylene (e.g., steam cracking, FCC) might not satisfy the increasing demand. Therefore, there is currently more industrial interest in having a catalytic process that provides high selectivity towards propylene.

Initial industrial demonstration of producing olefins from methanol was performed by Mobil in late 1980's. It was developed by modifying the MTG (Methanol-to-Gasoline) process which was already in operation. A ZSM-5 type catalyst (MFI topology, 10MR pores) was used. However, it can be stated that this zeolite catalyst was not designed for light olefin (ethylene/propylene) production as it favors long chain, branched paraffins and aromatics. Later on UOP and Norsk Hydro have developed the UOP/ Hydro MTO process, which employs a SAPO-34 type material as catalyst. SAPO-34 has the CHA topology and it is a more suitable catalyst for making light olefins. This is because the pore dimensions are smaller ( $8 \mathrm{MR})$, which makes this catalyst more selective towards ethylene and propylene. The ethylene/propylene ratio of the product stream can be tuned between 0.77 and 1.33. Lurgi has also developed a methanol based process called MTP (Methanol-to-Propylene). Pentasil-type zeolite catalyst (developed by Süd-Chemie), which is selective towards propylene, is used. Both UOP/Hydro and Lurgi are operating demonstration plants in Norway. 
One important factor in having methanol based processes (e.g., MTO, MTP, MTG) is the location. Approximately $60 \%$ of proven natural gas reserves are in remote parts of the world. It is not economical to utilize or transport this "stranded" gas with conventional methods. Therefore, these resources are mostly untapped. Converting these resources into methanol allows easier access to the value added chains of chemical industry. Lower grade methanol is acceptable as feedstock for these plants, so there is no need to build costly purification units. Other gas-to-liquids technologies, such as the zeolite catalyzed methane-to-benzene process [16], are also beneficial with the same rationale. The methane-tobenzene process also generates $\mathrm{H}_{2}$ as product, which will be in increasingly higher demand in the future, as it will be used more commonly as a fuel (i.e., hydrogen economy) and will be required for most of the other processes for raw material change. In the future, methane refineries can be expected to make better use of this raw material. In Fig. 4 possible routes for utilizing natural gas as a raw material in chemical industry are illustrated.

During the last decade the increase in coal price has been much less than the increase in crude oil or natural gas prices. This trend can make coal an attractive raw material for the chemical industry. Coal can be converted to syngas via the coal gasification process. The produced syngas can then be converted into methanol. Starting with methanol, olefins can be obtained by utilizing the zeolite catalyzed MTO, MTP or MTG technologies as described above. In Fig. 5 potential routes for utilizing coal as a raw material in chemical industry are presented.

Renewable resources can also be converted to base chemicals for industry such as ethanol or glycerol by fermentation or zeolite catalyzed chemical transformations. In Fig. 6 possible routes for utilizing bio-ethanol (obtained from renewable resources) as a raw material in chemical industry are illustrated. Biodegradable waste and other types of carbonaceous wastes also have the potential to be transformed into base chemicals via processes that make use of zeolite catalysts.

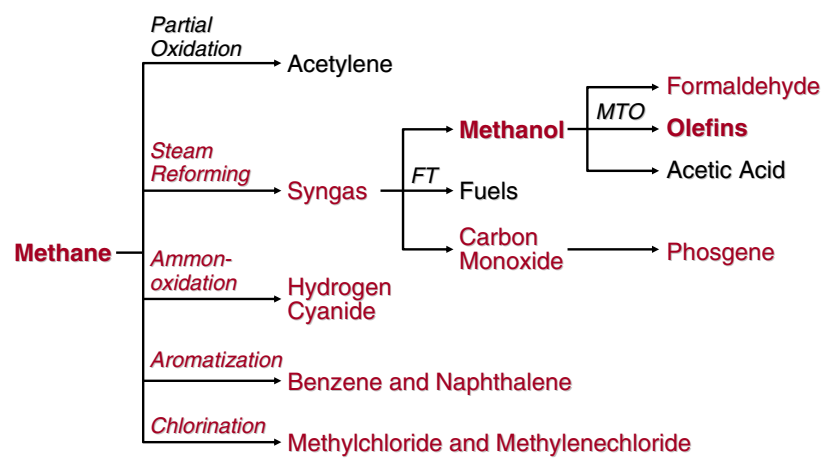

Fig. 4 Possible routes for utilizing natural gas as a raw material in chemical industry

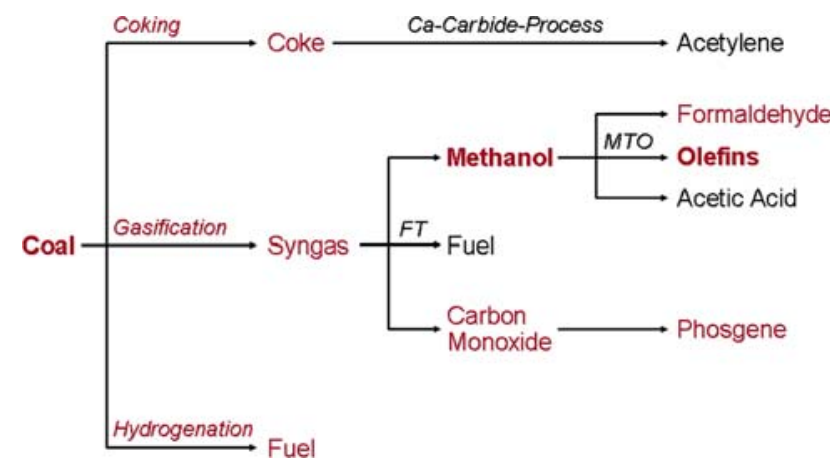

Fig. 5 Possible routes for utilizing coal as a raw material in chemical industry

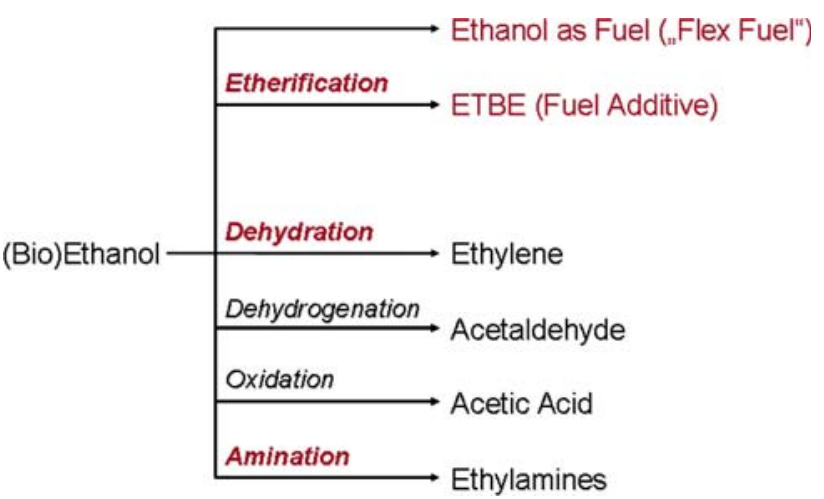

Fig. 6 Possible routes for utilizing ethanol (obtained from renewable resources) as a raw material in chemical industry

\section{Strategies in the Search for Novel Zeolites}

Small- and medium-pore zeolites are of great interest for the chemical industry due to the commercial potential they present in many processes dealing with molecules in this size regime. However, the focus of synthetic zeolite research in the last two decades has been on ultra large-pore structures. In the search for new framework topologies, various successful strategies have been explored, such as introducing fluoride as a mineralizer, substitution of $\mathrm{Si}$ in the lattice by other suitable atoms (e.g., Ge), charge density mismatch and synthesis in ionothermal media [17, 18]. Another highly prolific approach for synthesis of novel zeolites is the use of tailor-made structure-directing agents (SDA). This method resulted in many new and interesting zeolites; however, some of these large and exotic structure-directing agents are rather expensive. To address this issue, another methodology was developed, where a small amount of the particular structure-directing agent was used to drive the nucleation towards the desired structure, and other templating functions such as pore-filling and control of $\mathrm{pH}$ were fulfilled by an additional, low-cost SDA [17, 19].

The topotactic condensation of layered silicates into zeolitic frameworks also offers promise as a strategy for 
Fig. 7 Powder XRD pattern of RUB-39. Red lines represent the reference peak positions for RUB-39

Fig. 8 Powder XRD pattern of RUB-41. Red lines represent the reference peak positions for RUB-41

Fig. 9 SEM images of RUB-39 (a) and RUB-41 (b)
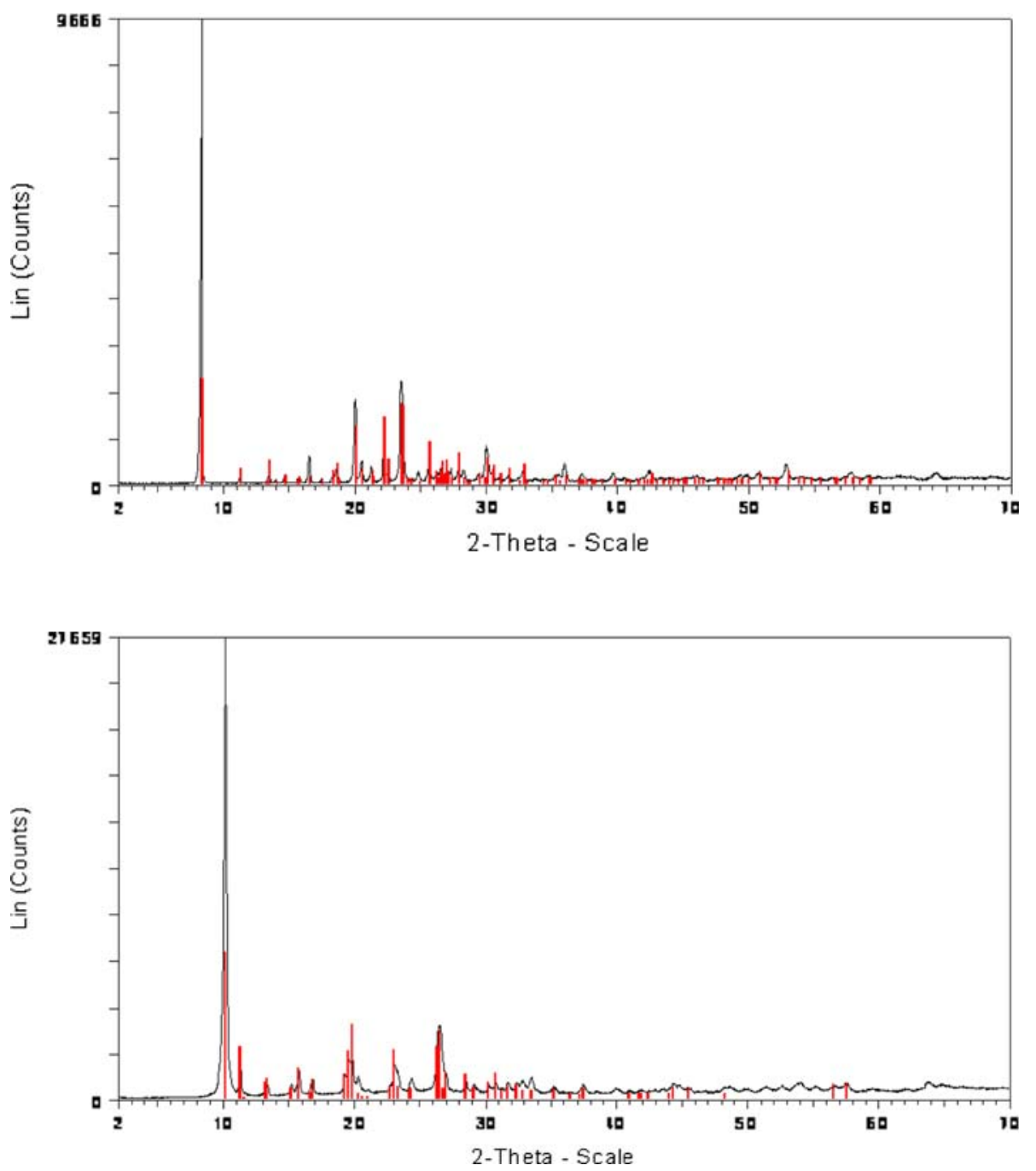

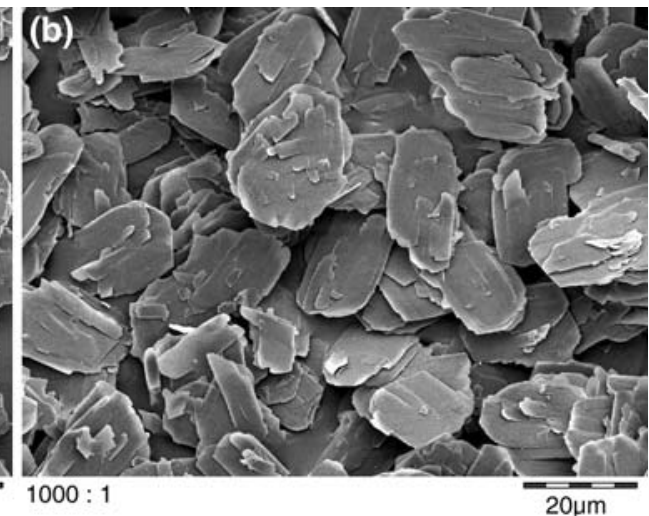

obtaining new framework topologies. A recent successful example of this approach is the conversion of layered silicate RUB-39 into zeolite RUB-41 [20], which will be elucidated here as a model case for discovery and exploration of novel zeolites in chemical industry. RUB-39 is a previously unknown hydrous layered silicate [21] (Fig. 7) and its controlled calcination results in a new zeolite named RUB-41 (Fig. 8), which was assigned the RRO topology. The typical synthesis procedure for RUB-39 and its conversion to RUB-41 are explained elsewhere [20]. SEM and TEM images of RUB-39 and RUB-41 are presented in Figs. 9 and 10 (a, b), respectively. In these 
Fig. 10 TEM images of RUB39 (a) and RUB-41 (b)
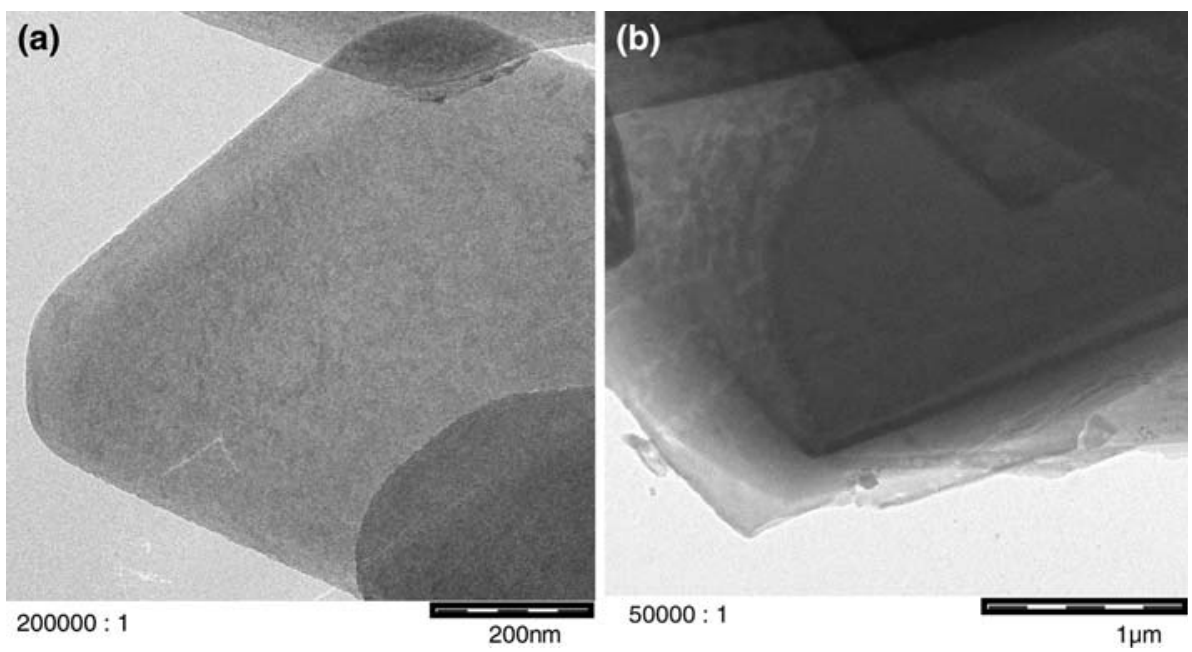

images the typical plate-like morphology of RUB-39 and RUB-41 can be observed.

RUB-41 is an interesting material that has a 2-dimensional channel system, which forms 8MR and 10MR pore openings, and typically has surface areas that exceed $500 \mathrm{~m}^{2} / \mathrm{g}$. Adsorption studies using small hydrocarbons showed stronger adsorption of alkenes compared to alkanes [20]. Liquid phase separation experiments on RUB-41 resulted in unusual trends of preferential adsorption, where uptake of trans-2-butene (critical diameter $=0.431 \mathrm{~nm}$ ) and cis-2-butene (critical diameter $=0.494 \mathrm{~nm}$ ) was favored over 1-butene (critical diameter $=0.446 \mathrm{~nm}$ ) [22]. Typically, in small pore zeolites the order of preference follows the order of critical diameter, hence the trans-2butene is favored over 1-butene and cis-2-butene [22]. The behavior of RUB-41 likely stems from the unique pore architecture of the RRO topology, where pore distortion leads to a pronounced selectivity. This finding demonstrates the potential of utilizing RUB-41 for a commercially attractive direct liquid-phase separation process to isolate pure 1-butene from a butene mixture [22]. It was also shown that insertion of functional $\mathrm{T}$-atoms into the silicate framework is possible, which makes this zeolite attractive for many applications in catalysis.

Recently, a new methodology for postalkoxysilylation of the layered silicate precursors to get new crystalline framework structures with expanded pore openings has been developed [23]. These interlayer expanded zeolites are thermally and hydrothermally stable. Utilization of this approach for layered precursors with MWW topology, generated catalysts that were more active in a variety of reactions involving bulky molecules, potentially due to the enhanced diffusion in the framework as a result of the wider interlayer pore openings [23]. This new strategy offers promise as a way to design catalysts based on the dimensional requirements of a reaction, and is likely to be employed by chemical industry.

\section{Conclusions and Outlook}

It can be stated that zeolites are of great interest for the chemical industry, especially due to their current and potential applications in catalysis. Even though synthetic zeolites have been used by industry for decades, prospects are still high for new structures and applications. Being the catalysts that can provide the much-needed selectivity towards base chemicals, zeolites will play a critical role in the quest for raw material change. Since there are an infinite number of possible zeolitic framework structures, it can be expected that academic and industrial research activities in this field will continue to be vigorous.

Acknowledgment Authors would like to express their appreciation to the members of the BASF-INCOE (International Network of Centers of Excellence) project: Prof. Xinhe Bao, Prof. Dirk De Vos, Prof. Hermann Gies, Prof. Takashi Tatsumi, Prof. Feng-Shou Xiao, for the productive collaboration and fruitful discussions.

Open Access This article is distributed under the terms of the Creative Commons Attribution Noncommercial License which permits any noncommercial use, distribution, and reproduction in any medium, provided the original author(s) and source are credited.

\section{References}

1. National Research Council (1992) In: Catalysis Looks to the Future, (Panel on New Directions in Catalytic Science and Technology), National Academy Press, Washington D.C., pp 1, 18

2. Bein T (2007) In: Cejka J, van Bekkum H, Corma A, Schüth F (eds) Introduction to Zeolite Science and Practice, 3rd revised edn. Elsevier, USA, pp 611-657

3. Yilmaz B, Sacco A, Deng J (2007) Appl Phys Lett 90(15): $152101 / 1-152101 / 3$

4. Sakaguchi K, Matsui M, Mizukami F (2005) Appl Microbiol Biotechnol 67:306-311

5. Lauriente DH, Inoguchi Y (2005) In: The Chemical Economics Handbook, SRI consulting, 599.1000 F, pp 6-8, 14

6. Bellussi G (2004) Stud Surf Sci Catal 154 A:53-65 
7. Maesen T (2007) In: Cejka J, van Bekkum H, Corma A, Schüth F (eds) Introduction to Zeolite Science and Practice, 3rd revised edn. Elsevier, USA, pp 1-12

8. Yamashita K (1995) Koatsu Gasu 32(5):412-416

9. Ichihashi H (2005) Shokubai 47(3):190-195

10. Izumi Y, Ichihashi H, Shimazu Y, Kitamura M, Sato H (2007) Bull Chem Soc Japan 80(7):1280-1287

11. Sasaki Y, Fukatsu M (1998) Catal Survey Japan 2(2):199-205

12. Oguchi W, Tsuji K, Tatsumi T, Wu P (2002) PCT Int Appl, WO2002028774

13. Ogawa T (2000) Eur Pat Appl, EP1041073

14. Tsuneki H, Kirishiki M, Oku T (2007) Bull Chem Soc Japan 80(6): 1075-1090

15. Diercks R, Arndt J-D, Freyer S, Geier R, Machhammer O, Schwartze J, Volland M (2008) Chem Eng Technol 31(5):631637
16. Ichikawa M (2007) J Japan Inst Energy 86:249-255

17. Wilson ST (2007) Stud Surf Sci Catal 170 A:3-18

18. Burton AW, Zones SI (2007) In: Cejka J, van Bekkum H, Corma A, Schüth F (eds) Introduction to Zeolite Science and Practice, 3rd revised edn. Elsevier, USA, pp 137-179

19. Zones SI, Hwang S-J (2002) Chem Mater 14(1):313-320

20. Wang YX, Gies H, Marler B, Mueller U (2005) Chem Mater 17:43-49

21. Wang YX, Gies H, Lin JH (2007) Chem Mater 19:4181-4188

22. Tijsebaert B, Varszegi C, Gies H, Xiao FS, Bao X, Tatsumi T, Mueller U, De Vos D (2008) Chem Commun 19:2480-2482

23. Wu P, Ruan J, Wang L, Wu L, Wang Y, Liu Y, Fan W, He M, Terasaki O, Tatsumi T (2008) J Am Chem Soc 130:8178 